\title{
ВЛИЯНИЕ РАЗЛИЧНЫХ МЕТОДОВ ЛЕЧЕНИЯ СИНДРОМА ИШЕМИИ-РЕПЕРФУЗИИ НА РИСК НЕБЛАГОПРИЯТНОГО ИСХОДА ЗАБОЛЕВАНИЯ
}

\begin{abstract}
EFFECT OF DIFFERENT TREATMENTS
FOR ISCHEMIA-REPERFUSION
SYNDROME ON THE RISK OF ADVERSE
OUTCOME OF THE DISEASE
D. Kutetov
Summary. Aims: to evaluate the influence of methods of treatment
of the syndrome of ischemia-reperfusion (SIR) for the risk of adverse
(fatal) outcome. Materials and methods: the study included 92 patients
(85 men and 7 women) aged from 50 to 92 years (mean age of $68.4 \pm 3.5$
years) with SIR, which arose after operations for critical limb ischemia
(CLI). For 1-day stay in the intensive care unit and intensive therapy
in all patients there was an increase in the level of key markers SIR:
creatine phosphokinase (CPK) and myoglobin. Recorded uremia, decline
in urine output <0.5 ml/kg/hour. Was diagnosed with clinical and
laboratory signs of acute kidney injury (AKI). Results: it is established
that on the background of conducting therapeutic plasma exchange
(TPE) observed a statistically significant decrease in the concentrations
of (PK and myoglobin. After the procedure hemodiafiltration (HDF) on-
line recorded a statistically significant decrease in urea and creatinine,
increase in the rate of diuresis. Conclusions: noted that the highest
absolute risk of adverse outcome SIR in patients after surgery for CLI,
was recorded in the treatment of patients with only conservative
medical therapy, and the smallest in the application schema: TPE+HDF
on-line.
\end{abstract}
Keywords: syndrome of ischemia-reperfusion injury, critical limb ischemia, acute kidney injury.
Жигалова Мария Сергеевна

Аспирант, ФГБУ ДПО «Центральная государственная медицинская академия

Управления делами президента РФ»; ГБУз

«Научно-исследовательский институт скорой помощи им. Н.В. Склифосовского Департамента

Здравоохранения города Москвы»

mari-zhi91@mail.ru

Кутепов Дмитрий Евгеньевич

Д.м.н., профессор, ФГБУ ДПО «Центральная государственная медицинская академия Управления делами президента РФ»; «Клиническая больнича № 1» Управления делами президента РФ (Москва) kutepovde@gmail.com

Пасечник Игорь Николаевич

Д.м.н., профессор, заведующий кафедрой Анестезиологии и реаниматологии ГБУ ДПО «Центральная государственная медицинская академия Управления делами президента РФ» pasigor@yandex.ru

Аннотация. Цель исследования: оценить влияние методов лечения синдрома ишемии-реперфузии (СИ) на риск наступления неблагоприятного (летального) исхода. Методы: в исследование было включено 92 пациента (85 мужчин и 7 женщин) в возрасте от 50 до 92 года (средний возраст $68,4 \pm 3,5$ лет) с (ИР, возникшем после операций по поводу критической ишемии нижних конечностей (КИНК). В течение 1-х суток пребывания в отделении реанимации и интенсивной терапии у всех больных отмечалось повышение уровня основных маркеров СИР: креатинфосфокиназы (КФК) и миоглобина. Зафиксирована гиперазотемия, снижение темпа диуреза $<0,5$ мл/кг/час. Были диагностированы клинико-лабораторные признаки острого повреждения почек (ОПП). Результаты: установлено, что на фоне проведения плазмообмена (П0) наблюдается статистически значимое снижение концентрации КФК и миоглобина. После проведенной процедуры гемодиафильтрации (ГДФ) online зафиксировано статистически значимое снижение мочевины и креатинина, увеличение темпа диуреза. Заключение: отмечено, что наибольший абсолютный риск неблагоприятного исхода СИР у больных после операции по поводу КИНК, регистрировался при лечении пациентов с использованием только консервативной медикаментозной терапии, а наименьший — при применении схемы: П0+ГДФ online.

Ключевые слова: синдром ишемии-реперфузии, критическая ишемия нижних конечностей, острое повреждение почек. 


\section{Ввемение}

C индром ишемии-реперфузии (СИР) представляет собой патологическое состояние, которое развивается в результате восстановления артериального кровотока в участке раннее ишемизированного органа или сегмента конечности $[1,4]$.

Врачи отделений реанимации и интенсивной терапии (ОРИТ) в последние годы все чаще сталкиваются с данной проблемой у пациентов, подвергшихся реконструктивным операциям по поводу критической ишемии нижних конечностей (КИНК) $[1,2,10]$.

В основе патогенеза СИР лежит повреждение ферментных систем биологического окисления в условиях длительной ишемии. В ходе последующего восстановления магистрального кровоснабжения происходит выраженное увеличение продукции активных форм кислорода (АФК). [4]. Вступая во взаимодействие с клеточными мембранами, АФК вызывают перекисное окисление липидов, изменение структуры белков с увеличением проницаемости, в результате чего наблюдается повреждение эндотелия и нарушение микроциркуляции $[4,6]$.

В условиях длительной ишемии происходит массивное разрушение мышечной ткани, что приводит к высвобождению миоглобина, который выпадает в осадок в виде кислого гематина, вызывая закупорку восходящей части петель нефронов. Являясь эндогенным токсином, миоглобин, наряду с микроциркуляторными нарушениями, играет значительную роль в развитии острого канальцевого некроза, что, в свою очередь, лежит в основе развития острого повреждения почек (ОПП) $[3,5]$.

Исходом прогрессирования СИР является развитие полиорганной недостаточности (ПОН), включающей сердечно-сосудистую, дыхательную, почечную недостаточность. Превалирующим является острое ОПП, что в свою очередь требует проведение экстракорпоральных методов лечения (ЭМЛ) $[7,9]$.

В литературе описаны случаи применения ЭМЛ у пациентов, перенесших ишемическое повреждение почек [2]. В основе действия ЭМЛ на организм больного лежит снижение уровня интоксикации, коррекция уремических нарушений, контроль водно-электролитного и кислотно-основного обмена [3]. Несмотря на положительные результаты, сведения о применении ЭМЛ у больных с СИР по-прежнему ограничены. На сегодняшний день лечение пациентов с данной патологией в большинстве случаев ограничено проведением медикаментозной терапии (МТ) [8].
Цель исследования: оценить влияние методов лечения СИР на риск наступление неблагоприятного (летального) исхода.

\section{Метолы}

В настоящей работе осуществлен анализ результатов комплексного обследования и лечения 92 хирургических пациентов с СИР (85 мужчин и 7 женщин). Возраст больных колебался от 50 до 92 лет (средний возраст $-68,4 \pm 3,5$ лет).

На момент поступления пациентов в ОРИТ тяжесть состояния по шкале APACHE II (Acute Physiology and

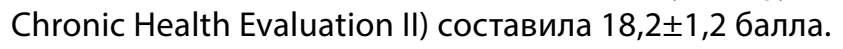

Все пациенты с СИР, потупившие в отделение реанимации и интенсивной терапии (ОРИТ) после реконструктивных операций по поводу КИНК были разделены на три группы:

Пациентам первой (контрольной) группы ( $\mathrm{n}=32)$ проводили МТ, включавшую инфузию растворов, антиагреганты, антикоагулянты.

Пациентам второй группы $(n=30)$ проводили МТ в сочетании с плазмообменом (ПО) в 1-е сутки после выполнения оперативного вмешательства, с целью элиминации высокомолекулярных соединений: креатинфосфокиназы (КФК), миоглобина.

Пациентам третьей группы ( $\mathrm{n}=30)$ МТ и ПО на 2-е сутки дополняли гемодиафильтрацией (ГДФ) online.

Всем больным проводилась инфузионная терапия (ИТ). Основными задачами проведения ИТ были: восполнение объёма циркулирующей крови, коррекция водно-электролитных нарушений, коррекция кислотно-основного состояния, коррекция нарушений проницаемости капилляров, коррекция гипотонии, обеспечение оптимальной гидратации, улучшение реологических свойств крови, поддержание осмолярности, коллоидно-осмотического давления. ИТ проводилась под контролем центрального венозного давления, частоты сердечных сокращений, артериального давления, темпа диуреза.

Однако, у данных больных на фоне проведения ИТ было отмечено прогрессирование клинических и лабораторных признаков СИР, что потребовало проведения ЭмЛ.

Основными показаниями для проведения ПО у больных с СИР было: повышение уровня КФК сыворотки крови в 10 и более раз от нормы, миоглобина в 2 
раза и более от нормы, снижение темпа диуреза $<0,5$ мл/кг/час.

ПО проводился на аппарате Multifiltrat (Фрезениус, Германия) с использованием плазмафильтра MPS0,5 P2 dry (Фрезениус, Германия). Параметры ПО: скорость кровотока 160-180 мл/мин., скорость плазмообмена 800-900 мл/ч. Объем удаленной плазмы за один сеанс

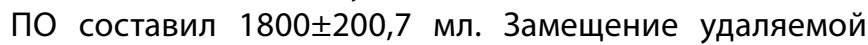
плазмы включало донорскую свежезамороженную плазму и раствор стерофундин в соотношении 2:1.

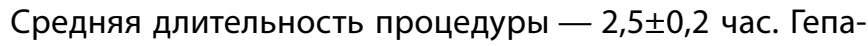
ринизация составила 5 тыс. единиц. Всего проведено 60 сеансов ПО.

Больным 3-й группы дополнительно проводили ГДФ online.

ГДФ online проводилась на аппарате «Искусственная почка» Dialog+ (B. Braun, Германия), диализатор Elisio-17 (Nipro, Бельгия). Параметры ГДФ online: скорость кровотока 250-300 мл/мин., скорость субституата 2500-2800 мл/мин, скорость диализирующего раствора 300-320 мл/мин, ультрафильтрация 500-2500 мл (в зависимости от степени гипергидротации). Длительность - от 3 до 4 час. Интервал между сеансами 36-48 часов. Гепаринизация - 4-5 тыс. единиц. Всего проведено 30 сеансов.

Для динамического наблюдения за параметрами гомеостаза был использован комплекс клинико-лабораторных показателей с определением в плазме уровня: КФК, миоглобина, креатинина, мочевины, лактата. Исследование всех биохимических показателей проводили на автоматическом анализаторе OLYMPUSAU2700 (Япония). Оценивали суточный диурез. Обследование проводили при поступлении больного в ОРИТ (исход), на 1-е, 2-е и 7-е сутки наблюдения.

Обработку данных проводили с помощью стандартных статистических программ Microsoft Excel. Величины средних значений признаков указаны в границах $\mathrm{M} \pm$. Степень изменения признака считали достоверной при величине возможной ошибки (р) меньше 0,05 в сравнении с исходными данными.

\section{Результаты и обсужАение}

У больных 1-й группы в 1-е сутки было отмечено достоверное повышение уровня КФК, миоглобина, креатинина, мочевины, снижение темпа диуреза (табл. 1). На фоне проведения МТ на 2-е сутки наблюдения в ОРИТ статистически значимых изменений не было зафиксировано (табл. 1). Тенденция к восстановлению диуреза и снижению уровня КФК, миоглобина, мочеви- ны и креатинина наблюдалась только к 7-м суткам: уровень КФК снизился в 2 раза ( $p<0,05)$, уровень миоглобина в 1,5 раза $(p<0,05)$, уровень мочевины и креатинина снижался в 1,4 раза $(\mathrm{p}<0,05)$, лактата - в 1,3 раза. Отмечено увеличение суточного диуреза в 2,2 раза $(p<0,05)$. Сроки пребывания больных 1-й группы в ОРИТ составило 16,6士4,3 суток. Летальность больных, которым проводилась МТ, составила $12,5 \%$.

У пациентов 2-й группы на 1-е сутки наблюдения было отмечено лабораторное повышение всех контролируемых показателей и снижение диуреза (табл. 1). После проведенного ПО зафиксировано снижение КФК в 2 раза $(p<0,05)$, миоглобина в 1,8 раз $(p<0,05)$, лактата в 1,8 раз $(p<0,05)$, увеличение диуреза в 2 раза $(p<0,05)$. Подобная динамика наблюдалась на протяжении всего времени пребывания в ОРИТ. Однако, уровень мочевины и креатинина оставались по-прежнему высокими. Снижение уровня данных маркеров ОПП было отмечен только на 7-е сутки лечения (табл. 1), при этом, обсуждаемые показатели превышали нормальные значения. Продолжительность пребывания в ОРИТ составила $12,2 \pm 1,6$ суток, а летальность - 6,6\%.

У пациентов 3-й группы на 1-е сутки наблюдения было отмечено лабораторное повышение всех контролируемых показателей, снижение диуреза (табл. 1). После проведенного ПО ожидаемо зафиксировано снижение КФК в 1,9 раз ( $p<0,05)$, миоглобина в 1,9 раз $(p<0,05)$, лактата в 2 раза $(p<0,05)$, увеличение диуреза в 2,4 раза $(p<0,05)$. Однако, уровень мочевины и креатинина превышали нормальные значения. После проведения ГДФ online на 2-е сутки наблюдения в ОРИТ отмечено статистически значимое уменьшение признаков гиперазотемии: уровень креатинина снизился в 2,5 раза $(\mathrm{p}<0,05)$, мочевины в 1,5 раза. Отмечено возрастание темпа диуреза в 5,2 раза $(p<0,05)$. Подобная тенденция прослеживалась на всем периоде лечения в ОРИТ (табл. 1). Продолжительность госпитализации в ОРИТ составила 7,2ะ1,08 суток, показатель летальности- 3,3\%.

Для того, чтобы оценить риск неблагоприятного исхода (летального исхода), а также выявить специфику влияния определенных методов лечения, среди которых МТ, ПО, ПО+ГДФ online, на возможность проявления такого исхода, мы сравнили группы пациентов с СИР.

Оценка была произведена по показателям абсолютного риска (АР), который указывает на коррелят летальности пациентов и реализуемых методов лечения. Выражение доли риска летального исхода, который зависит от того или иного применяемого метода лечения, в виде доли абсолютного риска было использовано, 
Таблица 1. Динамика лабораторных показателей у пациентов с СИР

\begin{tabular}{|c|c|c|c|c|c|c|c|c|c|c|c|c|}
\hline \multicolumn{4}{|l|}{ 1-я группа } & \multicolumn{4}{|c|}{ 2-я группа } & \multicolumn{4}{|l|}{ 3-я группа } & \multirow[b]{2}{*}{ 7сут } \\
\hline $\begin{array}{l}\text { Показа- } \\
\text { тели }\end{array}$ & исход & $1 \mathrm{cyт}$ & 2 сут & 7сут & исход & 1сут & 2 сут & 7сут & исход & 1 сут & 2сут & \\
\hline $\begin{array}{l}\text { Лактат } \\
\text { Ммоль/л }\end{array}$ & $\begin{array}{l}2,5 \\
\pm 1,08\end{array}$ & $\begin{array}{l}2,2 \\
\pm 1,00\end{array}$ & $\begin{array}{l}2,1 \\
\pm 1,00\end{array}$ & $\begin{array}{l}1,8 \\
\pm 1,02^{*}\end{array}$ & $\begin{array}{l}2,6 \\
\pm 1,12\end{array}$ & $\begin{array}{l}1,4 \\
\pm 0,4 \\
* * *\end{array}$ & $\begin{array}{l}1,2 \\
\pm 0,2 \\
* * *\end{array}$ & $\begin{array}{l}1,1 \\
\pm 0,2 \\
* * *\end{array}$ & $\begin{array}{l}2,4 \\
\pm 1,02\end{array}$ & $\begin{array}{l}1,2 \\
\pm 0,6 \\
* * *\end{array}$ & $\begin{array}{l}0,9 \\
\pm 0,4 \\
* * *\end{array}$ & $\begin{array}{l}0,8 \\
\pm 0,2 \\
* * *\end{array}$ \\
\hline $\begin{array}{l}\text { КФК } \\
\text { Ед/л }\end{array}$ & $\begin{array}{l}2988,4 \\
\pm 169,7\end{array}$ & $\begin{array}{l}2655,2 \\
\pm 188,4\end{array}$ & $\begin{array}{l}2001,7 \\
\pm 169,2\end{array}$ & $\begin{array}{l}1482,5 \\
\pm 129,3^{*}\end{array}$ & $\begin{array}{l}2558,2 \\
\pm 181,6\end{array}$ & $\begin{array}{l}1240,5 \\
\pm 115,2^{*}, * *\end{array}$ & $\begin{array}{l}886,7 \\
\pm 92,4 \\
* * *\end{array}$ & $\begin{array}{l}524,3 \\
\pm 41,6 \\
* * *\end{array}$ & $\begin{array}{l}2824,8 \\
\pm 200,4\end{array}$ & $\begin{array}{l}1485,2 \pm \\
124,6 \\
* * *\end{array}$ & $\begin{array}{l}760,4 \\
\pm 80,6 \\
* * *\end{array}$ & $\begin{array}{l}412,4 \\
\pm 26,8 \\
* * *\end{array}$ \\
\hline $\begin{array}{l}\text { Миогло- } \\
\text { бин } \\
\text { Нг/мл }\end{array}$ & $\begin{array}{l}138,3 \\
\pm 12,5\end{array}$ & $\begin{array}{r}126,6 \\
\pm 10,5\end{array}$ & $\begin{array}{l}120,1 \\
\pm 11,4\end{array}$ & $\begin{array}{l}92,9 \\
\pm 8,7^{*}\end{array}$ & $\begin{array}{l}140,5 \\
\pm 12,8\end{array}$ & $\begin{array}{l}76,2 \\
\pm 6,4 \\
* * *\end{array}$ & $\begin{array}{l}68,4 \\
\pm 5,2 \\
* * *\end{array}$ & $\begin{array}{l}59,2 \\
\pm 4,6 \\
* * *\end{array}$ & $\begin{array}{r}138,6 \\
\pm 14,5\end{array}$ & $\begin{array}{l}72,0 \\
\pm 5,8 \\
* * *\end{array}$ & $\begin{array}{l}65,2 \\
\pm 6,8 \\
* * *\end{array}$ & $\begin{array}{l}54,6 \\
\pm 6,2 \\
* * *\end{array}$ \\
\hline $\begin{array}{l}\text { Креатинин } \\
\text { Мкмоль/л }\end{array}$ & $\begin{array}{l}344,7 \\
\pm 21,8\end{array}$ & $\begin{array}{l}330,2 \\
\pm 20,5\end{array}$ & $\begin{array}{l}300,4 \\
\pm 26,2\end{array}$ & $\begin{array}{l}246,2 \\
\pm 18,4\end{array}$ & $\begin{array}{l}350,2 \\
\pm 28,4\end{array}$ & $\begin{array}{l}322,0 \\
\pm 26,2\end{array}$ & $\begin{array}{l}282,5 \\
\pm 16,3\end{array}$ & $\begin{array}{l}192,2 \\
\pm 14,5\end{array}$ & $\begin{array}{l}330,2 \\
\pm 29,0\end{array}$ & $\begin{array}{l}314,6 \\
\pm 28,2\end{array}$ & $\begin{array}{l}128 \\
4 \pm 10,2^{*}, * *\end{array}$ & $\begin{array}{l}87,6 \\
\pm 7,2 \\
* * *\end{array}$ \\
\hline $\begin{array}{l}\text { Мочевина } \\
\text { Ммоль/л }\end{array}$ & $\begin{array}{l}12,2 \\
\pm 1,35\end{array}$ & $\begin{array}{l}10,6 \\
\pm 1,16\end{array}$ & $\begin{array}{l}9,5 \\
\pm 1,11\end{array}$ & $\begin{array}{l}8,9 \\
\pm 0,88\end{array}$ & $\begin{array}{l}11,8 \\
\pm 1,04\end{array}$ & $\begin{array}{l}9,6 \\
\pm 1,00\end{array}$ & $\begin{array}{l}8,8 \\
\pm 0,6\end{array}$ & $\begin{array}{l}8,0 \\
\pm 0,2\end{array}$ & $\begin{array}{l}12,0 \\
\pm 1,2\end{array}$ & $\begin{array}{l}11,8 \\
\pm 1,4\end{array}$ & $\begin{array}{l}8,2 \\
\pm 0,6\end{array}$ & $\begin{array}{l}6,5 \\
\pm 0,8 \\
* * *\end{array}$ \\
\hline $\begin{array}{l}\text { Диурез } \\
\text { Мл/сут }\end{array}$ & $\begin{array}{l}400,5 \\
\pm 38,6\end{array}$ & $\begin{array}{l}415,8 \\
\pm 40,0\end{array}$ & $\begin{array}{l}550,0 \\
\pm 40,0\end{array}$ & $\begin{array}{l}912,5 \\
\pm 87,2^{*}\end{array}$ & $\begin{array}{l}420,7 \\
\pm 50,0\end{array}$ & $\begin{array}{l}900,2 \\
\pm 62,5^{*}, * *\end{array}$ & $\begin{array}{l}1500,0 \\
\pm 100,5^{*},{ }^{* *}\end{array}$ & $\begin{array}{l}1900,0 \\
\pm 120,5^{*}\end{array}$ & $\begin{array}{l}390,5 \\
\pm 30,0\end{array}$ & $\begin{array}{l}945,5 \\
\pm 80,2\end{array}$ & $\begin{array}{l}2050,0 \\
\pm 100,5^{*}\end{array}$ & $\begin{array}{l}2500,0 \\
\pm 150,5^{*}, * *\end{array}$ \\
\hline
\end{tabular}

Примечание: КФК — креатинфосфокиназа; (* - p<0,05 в исходными показателями; **- $<<0,05$ в сравнении с данными других групп).

Таблица 2. Абсолютный риск летального исхода при различных методах лечения пациентов с СИР

\begin{tabular}{|c|c|c|c|}
\hline \multirow{3}{*}{ Показатели } & \multicolumn{3}{|c|}{ Методы лечения } \\
\hline & MT & $\Pi ०$ & ПО+ГДФ on-line \\
\hline & \multicolumn{3}{|c|}{ Величина абсолютного риска } \\
\hline Пациенты & 0,125 & 0,066 & 0,033 \\
\hline
\end{tabular}

Примечание: МТ — медикаментозная терапия, ПО — плазмообмен, ГДФ — гемодиафильтрация

преимущественно, для того чтобы сравнить результаты разных способов лечения.

Результаты оценки риска наступления неблагоприятного исхода позволяют говорить о том, что наибольший AР имел место при лечении пациентов с использованием только медикаментозных методов лечения, а наименьший - при применении схемы ПО+ГДФ online. AP

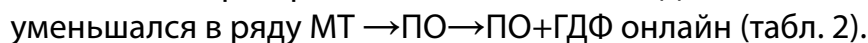

\section{ВывО $\triangle \mathrm{b}$}

После того, как у пациентов с КИНГ фоне прогрессирования СИР был восстановлен кровоток в ишемизи- рованной конечности, относительно часто отмечалось развитие ОПП. Стандартная медикаментозная терапия В конкретной ситуации не является эффективной и требует проведения ЭМЛ. Установлено, что наибольший АР летального исхода имел место при лечении пациентов с использованием только МТ, а наименьший - при схеме: ПО+ГДФ online.

Таким образом, применение ПО позволило снизить летальность в 1,9 раза по сравнению с МТ, а использование комбинации ПО и ГДФ online сопровождалось снижением летальности у пациентов с СИР в 3,8 раза по сравнению с больными 1-й группы и в 2 раза по сравнению с пациентами 2-й группы. 
ЛИТЕРАТУРА

1. Жигалова М.С., Кутепов Д.Е., Пасечник И.Н. Выбор оптимальной схемы лечения больных с синдромом ишемии-реперфузии, осложненным острым повреждением почек // Кремлевская медицина. Клинический вестник. 2020. № 1. С. 58-63.

2. Жигалова М.С., И.Н. Пасечник, Кутепов Д.Е. Эффективность применения плазмообмена у пациентов с синдромом ишемии-реперфузии нижних конечностей // Казанский медицинский журнал. № 2019. № 1. С. 130-134.

3. Кит 0.И., Димитриади С.Н., Франциянц Е.М., Ушакова Н.Д. Биомаркеры в диагностике острого повреждения почек после органосохраняющего хирургического лечения локализованного рака почки // Медицинский вестник Юга России. 2018. № (3). С. 77-83.

4. Кутепов Д.Е., Жигалова М.С., Пасечник И.Н. Патогенез синдрома ишемии-реперфузии // Казанский медицинский журнал. 2018 . № 99 (4). С. 640-644.

5. Смирнов А.В., Добронравов В.А., Румянцев А.Ш., Шилов Е.М., Ватазин А.В., Каюков И.Г., Кучер А.Г., Есаян А.М. Национальные рекомендации. Острое повреждение почек: основные принципы диагностики, профилактики и терапии. Часть I // Нефрология. 2016. № 20 (1). С. 79-104.

6. Bonventre Joseph V., Li Yang. Cellular pathophysiology of ischemic acute kidney injury // The Journal of clinical investigation. Am Soc Clin Investig. 2011. 3 121 (11). pp. 422.

7. Danobeitia Juan S., Djamali Arjang, Fernandez Luis A. The role of complement in the pathogenesis of renal ischemia-reperfusion injury and fibrosis // Fibrogenesis \& Tissue Repair. 2014. № 7. pp. 16.

8. Gilliland C. et al. Acute limb ischemia // Tech. Vasc. Interv. Radiol. 2017. № 20 (4). pp. 274-280.

9. Nisula S., Kaukonen K-M., Vaara S.T. et al. Incidence, risk factors and 90-day mortality of patients with acute kidney injury in Finnish intensive care units: the FINNAKI study // Intensive Care Med. 2014. № 39. pp. 420-428.

10. Obara H., Matsubara K., Kitagawa Y. Acute Limb Ischemia // Ann Vasc Dis. 2018. № 11(4). pp. 443-448.

( Ж Жигалова Мария Сергеевна ( mari-zhi91@mail.ru ), Кутепов Дмитрий Евгеньевич ( kutepovde@gmail.com ),

Пасечник Игорь Николаевич ( pasigor@yandex.ru ).

Журнал «Современная наука: актуальные проблемы теории и практики»

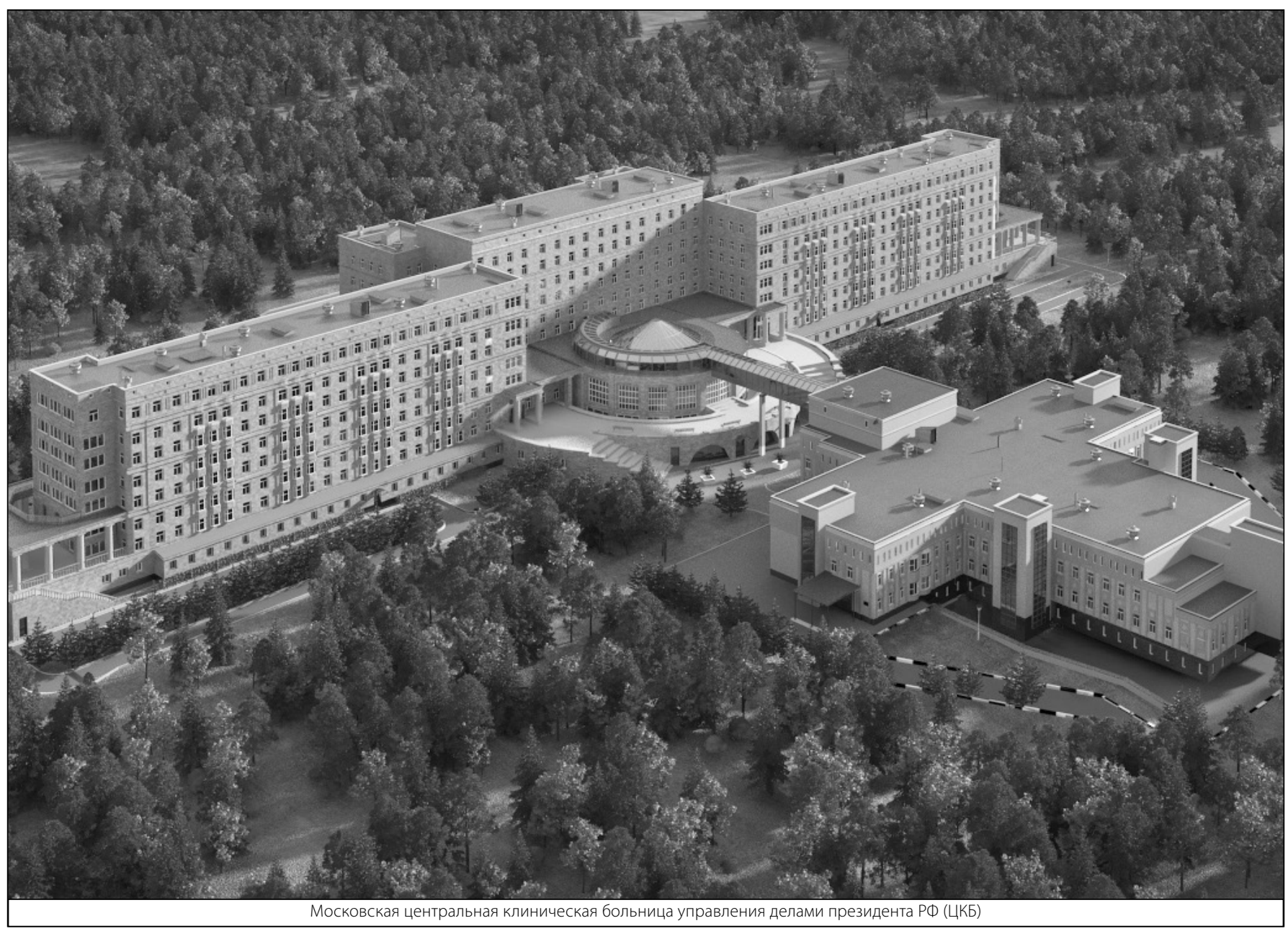

